\title{
Narrative review of clinical practice guidelines for treating people with moderate or severe traumatic brain injury
}

\author{
Lynn H. Gerber ${ }^{\mathrm{a}, \mathrm{b}, *}$, Rati Deshpande ${ }^{\mathrm{b}}$, Ali Moosvi ${ }^{\mathrm{b}}$, Ross Zafonte ${ }^{\mathrm{c}}$, Tamara Bushnik $^{\mathrm{d}}$, \\ Steven Garfinkel ${ }^{\mathrm{e}}$ and Cindy $\mathrm{Cai}^{\mathrm{e}}$ \\ ${ }^{a}$ Department of Health Administration and Policy, George Mason University, Fairfax, VA, USA \\ ${ }^{\mathrm{b}}$ Medicine Service Line, Inova Health System, Falls Church, VA, USA \\ ${ }^{\mathrm{c}}$ Department of Rehabilitation Medicine, Spaulding Rehabilitation Hospital, Charlestown, MA, USA \\ ${ }^{\mathrm{d}}$ Department of Rehabilitation Medicine, New York University Grossman School of Medicine, New York, USA \\ ${ }^{\mathrm{e}}$ American Institute for Research, Arlington, VA, USA
}

Received 26 January 2021

Accepted 21 April 2021

\begin{abstract}
.
BACKGROUND: Practice guidelines (CPGs) provide informed treatment recommendations from systematic reviews and assessment of the benefits and harms that are intended to optimize patient care. Review of CPGs addressing rehabilitation for people with moderate/severe traumatic brain injury (TBI), has not been fully investigated.

OBJECTIVE: Identify published, vetted, clinical practice guidelines that address rehabilitation for people with moderate/severe TBI.

METHODS: Six data bases were accessed using key word search terms: "Traumatic Brain Injury" and "Clinical Practice Guidelines" and "Rehabilitation". Further inclusions included "adult" and "moderate or severe". Exclusions included: "mild" and "concussive injury". Three reviewers read abstracts and manuscripts for final inclusion. The AGREE II template was applied for additional appraisal.

RESULTS: There were 767 articles retrieved using the search terms, 520 were eliminated because of content irrelevance; and 157 did not specify rehabilitation treatment or did not follow a process for CPGs. A total of 17 CPGs met all criteria and only 4 of these met all AGREE II criteria.

CONCLUSION: There are few CPGs addressing rehabilitation for people with moderate/severe TBI. More interventional trials are needed to determine treatment effectiveness. Timely and methodologically sound vetting of studies are needed to ensure CPG reliability and facilitate access to quality, effective treatment for people with moderate/severe TBI.
\end{abstract}

Keywords: Clinical practice guidelines, traumatic brain injury, rehabilitation

\section{Introduction}

In 2011, the National Academy of Medicine, formerly the Institute of Medicine, proposed a definition

*Address for correspondence: Lynn H. Gerber, MD, 4400 University Dr. MS 1B7, Fairfax, VA, 22030, USA. Tel.: +1 703993 1940; Fax: +1 703993 1926; E-mail: ngerber1@gmu.edu. for Clinical Practice Guidelines (CPGs) (Institute of Medicine (US) Committee on Standards for Developing Trustworthy Clinical Practice Guidelines, 2011). CPGs are statements that provide recommendations which are informed by a systematic review of evidence about diagnosis or treatment and include an assessment of the benefits and harms of alternative care options that are intended to optimize patient 
care (Institute of Medicine (US) Committee on Standards for Developing Trustworthy Clinical Practice Guidelines, 2011). They are developed to assist practitioners in making decisions about appropriate health care for a specific clinical condition.

Members of the committee that developed the report went further to identify additional recommendations so that there would be an assurance that CPGs would be trustworthy. The committee listed 6 points for people developing these guidelines to consider. These include: CPGs should be based on a systematic review of the existing evidence; be developed by a knowledgeable, multidisciplinary panel of experts; consider important patient subgroups and patient preferences; be based on an explicit and transparent process; provide a clear explanation of alternative care options and health outcomes, using quality of evidence and the strength of the recommendations; and be revised when new evidence warrants modifications of recommendations (Institute of Medicine (US) Committee on Standards for Developing Trustworthy Clinical Practice Guidelines, 2011).The recommendations for CPG development have been generally accepted and helped raise the standard for what is appropriate and reimbursable care.

CPGs help establish what is meant by quality medical care, reduce practice variation and ensure uniform utilization of treatments in order to establish standards of care and create performance measures that can be applied to patients with similar medical diagnoses/problems. Additionally, CPGs have educational value for practitioners, patients and care givers/family; and may help non-specialists extend quality practice in under-sourced specialties. CPGs are an important resource to health care consumers and providers. Significant obstacles to CPG adoption include access to resources and feasibility of implementation in low income areas (Patel et al., 2016).

Much has been written about the value of CPGs in improving quality health care. The importance of assuring the process by which they are developed, assuring the quality of the studies included in forming a decision about what to recommend for practice and the ease of access to CPGs are all important components of providing quality, timely and reliable care (Guyatt, 2006, 2011; Laine, 2011). In specialties such as rehabilitation, studies are infrequently randomized controlled trials. Clinical cohorts are often small and treatments while standard treatments, are highly individualized. This presents challenges for practitioners trying to determine best practices and level of evidence to support treatment planning. Despite these difficulties, when CPGs are properly performed, they help overcome some of these limitations (Kredo et al., 2016).

With respect to specifics about treating people post traumatic brain injury (TBI), there are significant benefits of having CPGs. For complex medical and biopsychosocial conditions, CPGs have the potential of bringing together recommendations for treatment from several disciplines to address this patient population's multi-domain problems. For example, TBI is a chronic illness whose impact affects mood, behavior, physical and intellectual function (Corrigan \& Hammond, 2013; Hammond, 2019, 2021). A wide variety of symptoms frequently follows from this injury; insomnia, depression and fatigue, to mention a few. Additionally, medical comorbidities may delay start of recovery, or/and degree of recovery (Malec et al., 2019). These include: hypertension, type 2 diabetes, rheumatoid arthritis, cancer, movement disorders, among others. CPGs can also provide a reliable review of literature, assessment of the level of evidence and best practices. Best practices do not meet the level of rigorous review required for CPGs, which depend upon a thorough and systematic review of published data from a variety of sources. CPGs report the different levels of evidence in their recommendations, assure the quality of the review process, rate and assess usefulness and practice experience. The absence of CPGs also may be the result of gaps in our current level of knowledge about treatment, a problem previously reported in a review of the literature about clinical rehabilitation research for people with TBI where it was reported that not much of the literature includes general rehabilitation and trials (Gerber et al., 2019).

Therefore, the motivation for this review is to determine which TBI-CPGs have been published that meet the criteria for inclusion for this review including: 1. clinical practice guidelines published between 2010-2020; 2. a stated process for providing reliable and trustworthy CPGs; and 3. that CPGs addressed rehabilitation and functional needs of people with TBI.

\section{Methods}

The following databases were searched for articles: PubMed, Cochrane Data Base, Ovid Medline, EMBASE, CINHAL and Web of Science. Selection criteria for the literature search included: "Traumatic Brain Injury AND Clinical Practice Guidelines AND 
Rehabilitation." Further inclusions included "Adult". Exclusionary terms included mild TBI or concussive injury. Additionally, a review from a general Google search that used the keywords mentioned, was performed to learn if there were CPGs from other sources that are not identified through the databases listed above that met inclusion criteria and had no exclusions. This included searching websites from well-known organizations, foundations and professional societies addressing practice guidelines for
TBI. An additional inclusion criterion, determined after articles were read in full, was to determine that development of guidelines followed an established, accepted vetting process such as that by Oxford, or United States Preventive Services Task Force or Institute of Medicine (Institute of Medicine (US) Committee on Standards for Developing Trustworthy Clinical Practice Guidelines, 2011; Oxford Centre for Evidence-based Medicine, 2019; U.S. Preventive Services Task Force, 2018). The key elements

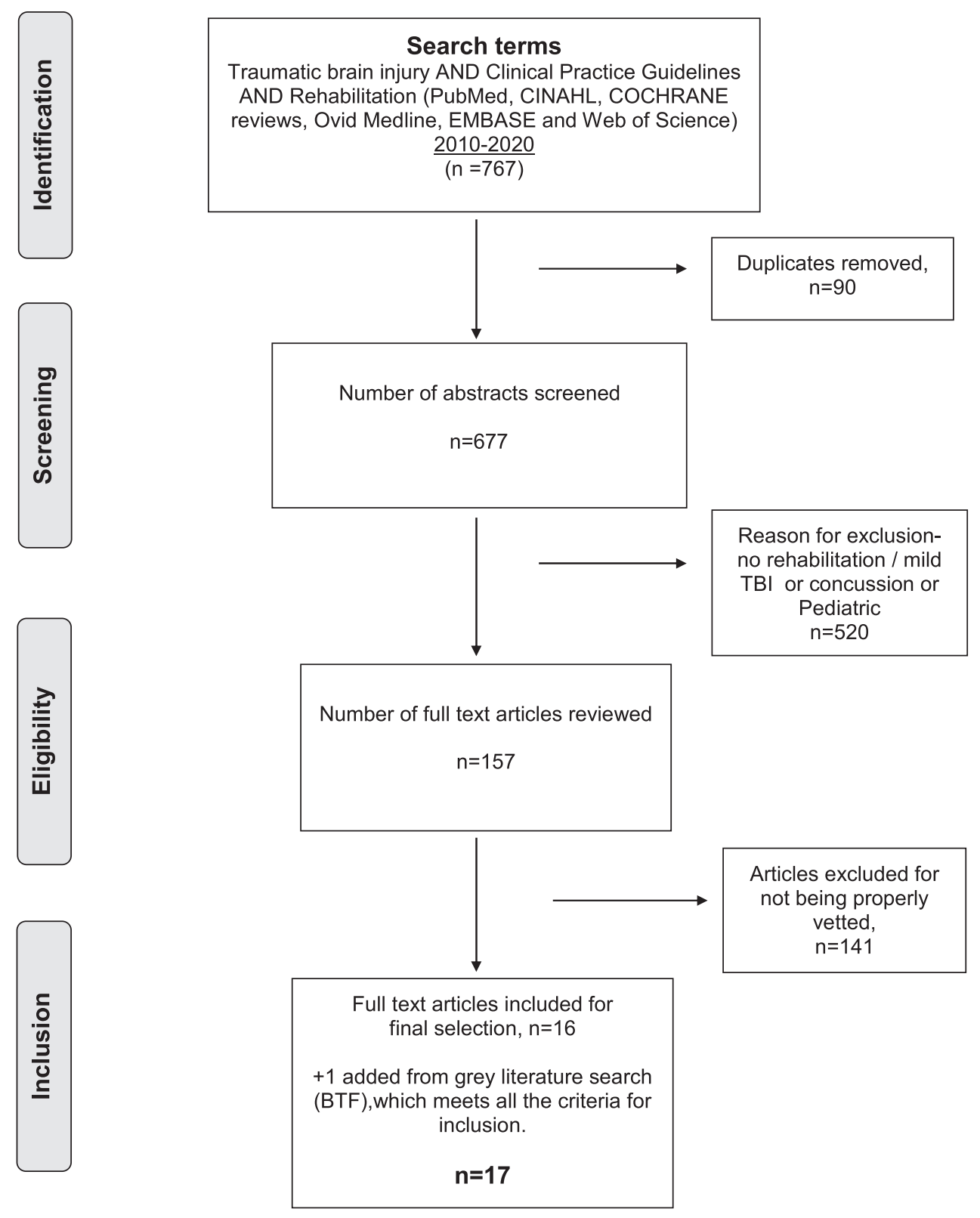

Fig. 1. The PRISMA flowchart of the results from the database searches. 
for these vetting processes include some or all of the following: establishing transparency, managing conflicts of interest, developing guidelines for group composition, establishing a process for systematic literature review, establishing foundations of evidence for and strength of recommendations, articulating recommendations, establishing a process and committee for external review, and updating recommendations. Additionally, all articles were reviewed to determine whether they addressed rehabilitation. Criteria for qualifying as rehabilitation was that the CPG aimed to improve, maintain, or restore human function and/or provide treatment(s) designed to facilitate the process of recovery from injury, illness, or disease to as normal a functional condition as possible. The definition of the word "function" in this context is taken from the International Classification of Functioning, Disability and Health (ICF). Functioning, as used in the ICF descriptions is defined as "a dynamic interaction between her or his health conditions, environmental factors, and personal factors" (World Health Organization, 2018). The criterion for "rehabilitation intervention" was that there be a specific rehabilitation treatment recommended, not a general comment about "refer to rehabilitation, physical or occupational therapy" and that a functional outcome measure was included in the methods section. The search process followed the PRISMA algorithmic approach using the inclusion and exclusion criteria (Moher et al., 2015). A schematic using this approach is presented in Fig. 1. The specific articles were reviewed as described above and selected for inclusion after meeting all criteria. The summaries of the articles reviewed which we selected for this report include: title of the article; the journal in which it was published; authors and the professional affiliation of the endorsing organization (E.g. Monash University, French Society of Physical and Rehabilitation Medicine et al); the setting for which the guidelines apply (E.g. acute care, post-acute care, community-based care) (Table 1). A brief summary of the recommendations made by each of the guidelines is also provided. Information gathered from publications addressing TBI and rehabilitation which did not undergo a standard vetting process by the practice guidelines developers, but had informational value or included TBI as one of many conditions in the guideline development process (E.g. disorders of consciousness or stroke), is also provided for informational purposes (Table 2).

Additionally, the publications were evaluated using the Appraisal of Guidelines for Research and
Evaluation (AGREE II) (3). The AGREE II template is a validated instrument for appraising CPGs (https://www.agreetrust.org/wp-content/uploads/ 2016/02/AGREE-Reporting-Checklist-2016.pdf) which comprises 23 questions grouped into 6 domains: 1. scope and purpose of CPG; 2. Stakeholder involvement; 3 . Rigor of development; 4 . Clarity of presentation; 5. Applicability; 6 editorial independence (Brouwers et al., 2016). All CPGs that met inclusion criteria were further assessed for meeting AGREE II requirements.

\section{Results}

There were 767 articles retrieved when applying the search terms. There were 90 duplicates leaving 677 for abstract review. Following this, 520 were eliminated after full reading of the manuscript they did not meet inclusion criteria. Some did not address rehabilitation or addressed mild TBI or concussive injury, leaving 157 articles for review. One hundred forty-one did not specify any vetting or standard review process, leaving 16 that met inclusion criteria and no exclusion criteria. A Google search for key search terms identified one CPG that had not been retrieved from the database searches. This was a CPG from the Brain Injury Foundation and was included in the final count. An additional summary publication included CPGs and other aspects about TBI management and diagnosis but did not meet criteria for CPGs (Togher et al., 2014). The total number of CPGs for TBI (excluding mild/concussive injury) is 17 (Bayley et al., 2014; Brain Trauma Foundation, 2016; Doncevic \& Boerman, 2010; Honan et al., 2019; Levine, 2016; Maas et al., 2017; MuCulloch et al., 2016; Ontario Neurotrauma Foundation, 2015; Pattuwage et al., 2017; Ponsford, 2014a, 2014b; Scholten et al., 2017; Stergiou-Kita et al., 2012; Tate et al., 2014; Togher et al., 2014; Uomoto, 2012; Velikonja et al., 2014). These data are presented using the PRISMA flow diagram (Fig. 1 and Table 1). Tables for CPGs meeting all criteria included: title of the article and authors; the journal in which it was published; the professional affiliation of the endorsing organization (E.g. Brain Injury Foundation, International Group of Researchers and Clinicians (INCOG) etc.); the setting for which the guidelines apply (E.g. acute care, post-acute care, community-based care); and, which vetting criteria were used (E.g. IOM, Oxford, USPSTF, et al.). A brief summary of the recommendations made in each of the guidelines is also provided. 
Table 1

All entries have met criteria for inclusion and have no exclusions. One reference was added as a result of Google search that was not retrieved from the database searches

\begin{tabular}{|c|c|c|c|}
\hline $\begin{array}{l}\text { Title + Citations + } \\
\text { Reference number } \\
\text { in text + URL }\end{array}$ & Treatment guidelines & Journal/Sponsor & Level of evidence \\
\hline $\begin{array}{l}\text { 1. Management of Spasticity in } \\
\text { Moderate and Severe Traumatic Brain } \\
\text { Injury: Evaluation of Clinical Practice } \\
\text { Guidelines. Pattuwage L, Olver J, } \\
\text { Martin C, et al. J Head Trauma } \\
\text { Rehabil. 2017;32(2):E1-E12. } \\
\text { Doi:10.1097/HTR.0000000 } \\
\text { 000000234. } \\
\text { https://pubmed.ncbi.nlm.nih. } \\
\text { gov/27120291/ }\end{array}$ & $\begin{array}{l}\text { - Subacute, post care institutional care. } \\
\text { - Early interventions to treat spasticity in TBI through } \\
\text { pharmacological and non-pharmacological approaches } \\
\text { are vital. } \\
\text { - Mostly Nonpharmacological/noninvasive ways like physiotherapy, } \\
\text { splinting, casting, etc. are to begin with. } \\
\text { - Pharmacological approaches include use of Baclofen, Dantrolene } \\
\text { sodium, Tizanidine and Botulinum toxin A injections. }\end{array}$ & $\begin{array}{l}\text { Monash University, } \\
\text { Victoria, Australia }\end{array}$ & Level I \\
\hline $\begin{array}{l}\text { 2. Outcome Measures for Persons With } \\
\text { Moderate to Severe Traumatic Brain } \\
\text { Injury: Recommendations From the } \\
\text { American Physical Therapy } \\
\text { Association Academy of Neurologic } \\
\text { Physical Therapy TBI EDGE Task } \\
\text { Force. McCulloch KL, de Joya AL, } \\
\text { Hays K, et al. J Neurol Phys Ther. } \\
\text { 2016;40(4):269-280. } \\
\text { Doi:10.1097/NPT.0000000 } \\
\text { 000000145. } \\
\text { https://pubmed.ncbi.nlm.nih. } \\
\text { gov/27576089/ }\end{array}$ & $\begin{array}{l}\text { - Post care institutional setting. } \\
\text { - Standard outcome measures include } 15 \text { for body functions/ } \\
\text { structure, } 21 \text { activity measures, } 23 \text { for participation and } 29 \text { covered } \\
\text { more than } 1 \text { ICF domain. } \\
\text { - Recommendations made by TBI EDGE task force can help } \\
\text { clinicians and researchers to choose appropriate Oms in people } \\
\text { with mod to severe TBI for the continuum of care and } \\
\text { rehabilitation. }\end{array}$ & $\begin{array}{l}\text { American Physical } \\
\text { Therapy Association }\end{array}$ & Level I \\
\hline $\begin{array}{l}\text { 3. Outcome Instruments in } \\
\text { Moderate-To-Severe Adult Traumatic } \\
\text { Brain Injury:Recommendations for } \\
\text { Use in Psychosocial Research.Honan } \\
\text { CA, McDonald S, Tate R, et al. } \\
\text { Neuropsychol Rehabil. } \\
\text { 2019;29(6):896-916. } \\
\text { doi:10.1080/09602011. } \\
\text { 2017.1339616. } \\
\text { https://pubmed.ncbi.nlm.nih. } \\
\text { gov/28671050/ }\end{array}$ & $\begin{array}{l}\text { - Post care community setting. } \\
\text { - Recommendations includes } 56 \text { instruments for use in early } \\
\text { recovery, outcome and intervention studies. These } \\
\text { recommendations are organized according to the WHO's ICF } \\
\text { taxonomy. }\end{array}$ & $\begin{array}{l}\text { Moving Ahead: Centre } \\
\text { for Research } \\
\text { Excellence (CRE) in } \\
\text { Brain Recovery }\end{array}$ & Level not specified \\
\hline
\end{tabular}


Table 1

(Continued)

\begin{tabular}{|c|c|c|c|}
\hline $\begin{array}{l}\text { Title + Citations + } \\
\text { Reference number } \\
\text { in text + URL } \\
\end{array}$ & Treatment guidelines & Journal/Sponsor & Level of evidence \\
\hline $\begin{array}{l}\text { 4. Clinical Practice guidelines for } \\
\text { moderate to severe traumatic brain } \\
\text { injury by ONF-INESSS. Ontario } \\
\text { Neurotrauma Foundation, } 2015 \text {. } \\
\text { http://onf.org/our-programs/acquired- } \\
\text { brain-injury/systematic-reviews-abi- } \\
\text { guidelines-and-measurements/inesss- } \\
\text { onf-guideline-for-rehabilitation-of- } \\
\text { adults-with-moderate-to-severe-tbi }\end{array}$ & $\begin{array}{l}\text { - Acute, Subacute, Post care institutional and community settings. } \\
\text { - Extensive CPGs with recommendations from acute rehab to } \\
\text { community integration and participation. Key components } \\
\text { are-Management and disorders of consciousness, subacute } \\
\text { rehabilitation, promoting reintegration and participation, caregivers } \\
\& \text { families. Rehabilitation models stated with levels of evidence } \\
\text { and priority. }\end{array}$ & $\begin{array}{l}\text { Ontario Neurotrauma } \\
\text { Foundation }\end{array}$ & Level I \\
\hline $\begin{array}{l}\text { 5. France establishes guidelines for } \\
\text { treating neurobehavioral disorders } \\
\text { following traumatic brain injury. Levin } \\
\text { H. Ann Phys Rehabil Med. } \\
\text { 2016;59(1):74-77. } \\
\text { doi:10.1016/j.rehab.2015.06.005. } \\
\text { https://pubmed.ncbi.nlm.nih. } \\
\text { gov/26278163/ }\end{array}$ & $\begin{array}{l}\text { - Subacute, post care institutional \& community care. } \\
\text { - Recommendations include psycho-social dimensions of } \\
\text { rehabilitation apart from medical and neurological issues. } \\
\text { - Taking a note of patient's environment is important in addressing } \\
\text { behavioral and aggressive disorders post TBI. } \\
\text { - Use of CBT and Neuroleptics are recommended for post-acute and } \\
\text { chronic behavioral comportment disorders. }\end{array}$ & $\begin{array}{l}\text { La French Society of } \\
\text { Physical Medicine and } \\
\text { Rehabilitation } \\
\text { (SOFMER) }\end{array}$ & Level I \\
\hline $\begin{array}{l}\text { 6. INCOG guidelines for cognitive } \\
\text { rehabilitation following traumatic } \\
\text { brain injury: methods and overview. } \\
\text { Bayley MT; Tate R; Douglas JM; } \\
\text { Turkstra LS; Ponsford J; Stergiou-Kita } \\
\text { M; Kua A; Bragge P; INCOG Expert } \\
\text { Panel. Journal of Head Trauma } \\
\text { Rehabilitation. 29(4):290-306, } 2014 \\
\text { Jul-Aug. }\end{array}$ & $\begin{array}{l}\text { - Subacute, post care institutional settings. } \\
\text { - Recommendations include people with TBI have detailed } \\
\text { assessments of cognition after resolution of posttraumatic amnesia. } \\
\text { - Cognitive assessment and rehabilitation should be tailored to the } \\
\text { patient's neuropsychological profile, premorbid cognitive } \\
\text { characteristics, and goals for life activities and participation. } \\
\text { - Cognitive rehabilitation should be offered in the form of restorative } \\
\text { training, caregiver training, functional adaptation, education of } \\
\text { consequences post TBI, environmental manipulations. }\end{array}$ & $\begin{array}{l}\text { International Group of } \\
\text { Researchers and } \\
\text { Clinicians (INCOG) }\end{array}$ & Level I \\
\hline $\begin{array}{l}\text { 7. INCOG Recommendations for } \\
\text { Management of Cognition Following } \\
\text { Traumatic Brain Injury, Part I: } \\
\text { Posttraumatic Amnesia } \\
\text { (PTA)/Delirium. Ponsford, Jennie; } \\
\text { Janzen, Shannon; McIntyre, Amanda; } \\
\text { Bayley, Mark; Velikonja, Diana; Tate, } \\
\text { Robyn.Journal of Head Trauma } \\
\text { Rehabilitation: July/August } 2014 \text { - } \\
\text { Volume 29 - Issue } 4 \text { - p } 307-320 \text { doi: } \\
\text { 10.1097/HTR.0000000000 } \\
\text { 000074 }\end{array}$ & $\begin{array}{l}\text { - Subacute, post care institutional setting. } \\
\text { - Recommendations include PTA assessment daily using validated } \\
\text { tool until PTA / PTD resolution, Assessment of patient in PTA with } \\
\text { delirium assessment toll in order to better characterize them. } \\
\text { - Management of patients with PTA are avoiding restraint for } \\
\text { patients; allowing them to move freely, maintenance of calm } \\
\text { environment, Avoidance of overstimulation, Assessment of } \\
\text { visitor's' impact, Establishing strong means of communication, } \\
\text { Providing Repeated reassurances. } \\
\text { - Pharmacological intervention includes avoiding Neuroleptics as } \\
\text { they hamper the recovery and cognition post TBI. }\end{array}$ & $\begin{array}{l}\text { International Group of } \\
\text { Researchers and } \\
\text { Clinicians (INCOG) }\end{array}$ & Level I \\
\hline
\end{tabular}


8. INCOG recommendations for management of cognition following traumatic brain injury, part II: attention and information processing speed.Ponsford J; Bayley M; Wiseman-Hakes C; Togher L; Velikonja D; McIntyre A; Janzen S; Tate R; INCOG Expert Panel.Journa of Head Trauma Rehabilitation. 29(4):321-37, 2014 Jul-Aug.

9.INCOG recommendations for management of cognition following traumatic brain injury, part III: executive function and self-awareness Tate R; Kennedy M; Ponsford J;

Douglas J; Velikonja D; Bayley M; Stergiou-Kita M. Journal of Head Trauma Rehabilitation. 29(4):338-52, 2014 Jul-Aug.

10.INCOG recommendations for management of cognition following traumatic brain injury, part IV: cognitive communication. Togher L; Wiseman-Hakes C; Douglas J; Stergiou-Kita M; Ponsford J; Teasel R; Bayley M; Turkstra LS; INCOG Expert Panel. Journal of Head Trauma Rehabilitation. 29(4):353-68, 2014 Jul-Aug

11. INCOG recommendations for management of cognition following traumatic brain injury, part V: memory. Velikonja D; Tate R; Ponsford J; McIntyre A; Janzen S; Bayley M; INCOG Expert Panel. Journal of Head Trauma Rehabilitation. 29(4):369-86, 2014 Jul-Aug
- Subacute and post care institutional setting.

- Nonpharmacological approaches include Metacognitive strategy using everyday activity, Training in dual tasking, cognitive behavior therapy for addressing issues of information processing and attention post TBI.

- Pharmacological treatment recommendation is use of Methylphenidate for enhancing speed of information processing.

- Subacute, post care institutional setting.

- Interventions include metacognitive strategy training for patients with TBI having issues with problem solving, organization and planning, Strategies to improve the capacity to analyze and synthesize information should be used in patients with TBI having impaired reasoning skills.

- Direct corrective feedback should be used in people with TBI having impaired self-awareness.

- Group based interventions for executive and problem-solving deficits post TBI.

- Subacute, post care institutional \& community care.

- Guideline recommendation interventions to improve cognitive communication include recognition of rehab staff for communication competence and characteristics as part of communication partner, demands and priorities. Involvement of Speech pathologist for addressing the cognitive communication disorder post TBI is helpful.

- Cognitive communication rehabilitation program should be offered to rehearse communication skills in everyday life and work. Similar training should be provided to communication partners/ family.

- Group based interventions are strongly recommended to address the patient-identified communication deficits post TBI

- Subacute, post care institutional setting.

- Guideline recommendation interventions include Metacognitive and Instructional strategies for memory impairment in patients with TBI.

- Environmental supports and reminders in the form of Neuropage, Siri, Whiteboards, Smartphones, PDA, Notebooks, etc. are recommended for memory impairment post TBI

- External memory aids, Group based interventions and use of ACE inhibitors are other recommendations for memory impairment in TBI patients.
International Group of

Researchers and

Clinicians (INCOG)

Level 1

International Group of

Researchers and

Clinicians (INCOG)

International Group of

Level I

Researchers and

Clinicians (INCOG)

International Group of

Level I

Researchers and

Clinicians (INCOG) 
Table 1

(Continued)

\begin{tabular}{|c|c|c|c|}
\hline $\begin{array}{l}\text { Title + Citations + } \\
\text { Reference number } \\
\text { in text + URL }\end{array}$ & Treatment guidelines & Journal/Sponsor & Level of evidence \\
\hline $\begin{array}{l}\text { 12.Guidelines for the Management of } \\
\text { Severe Traumatic Brain Injury } \\
\text { 4th.edition,Sept.2016.Brain Trauma } \\
\text { foundation. } \\
\text { https://www.braintrauma.org/ } \\
\text { uploads/13/06/Guidelines_for_- } \\
\text { Management_of_Severe_TBI_ } \\
\text { 4th_Edition.pdf }\end{array}$ & $\begin{array}{l}\text { - Acute, subacute institutional care. } \\
\text { - Updated recommendations for acute to subacute care includes A } \\
\text { Large Frontotemporoparietal Decompressive Craniectomy to } \\
\text { reduce mortality and improve neurological outcomes in severe } \\
\text { TBI. Prophylactic Hypothermia is not recommended. } \\
\text { - Hyperventilation avoided for first } 24 \text { hours of injury and is } \\
\text { recommended for reducing ICP as a temporizing measure. } \\
\text { - Use of steroids is not recommended for reducing ICP. } \\
\text { - Feeding patients with basal caloric requirement by the fifth day is } \\
\text { vital. Transgastric jejunal feeding is recommended to reduce the } \\
\text { possibility ventilator-associated pneumonia. }\end{array}$ & Brain Trauma Foundation & Level I \\
\hline $\begin{array}{l}\text { 13.Best Practices in Veteran Traumatic } \\
\text { Brain Injury Care. APA Uomoto, Jay } \\
\text { M. PhD. Journal of Head Trauma } \\
\text { Rehabilitation: July/August } 2012 \text { - } \\
\text { Volume } 27 \text { - Issue 4 - p 241-243. } \\
\text { https://journals.lww.com/headtra } \\
\text { umarehab/Fulltext/2012/07000/ } \\
\text { Best_Practices_in_Veteran_ } \\
\text { Traumatic_Brain_Injury.1.aspx doi: } \\
\text { 10.1097/HTR.0b013e } \\
\text { 31825ee26a }\end{array}$ & $\begin{array}{l}\text { - Intuitional Post care. } \\
\text { Deflaborative efforts between the VA and the Department of } \\
\text { workgroup was established to advise the joint VA/DoD Health } \\
\text { Executive Council on the application and development of clinical } \\
\text { practice guidelines that translate empirical research to practice } \\
\text { implementation. } \\
\text { - Several clinical practice guidelines (CPGs) have been developed to } \\
\text { address an array of conditions seen in primary care, mental health } \\
\text { problems, military-related disorders, pain, rehabilitation practices, } \\
\text { and women's health issues. }\end{array}$ & Veterans Administration & Levels 1,2 \\
\hline $\begin{array}{l}\text { 14. Inter-professional Clinical Practice } \\
\text { Guideline for Vocational Evaluation } \\
\text { Following Traumatic Brain Injury: A } \\
\text { Systematic and Evidence-Based } \\
\text { Approach.Stergiou-Kita M, Dawson } \\
\text { D, Rappolt S. J Occup Rehabil. } \\
\text { 2012;22(2):166-181. } \\
\text { doi:10.1007/s 10926-011- } \\
\text { 9332-2. https://pubmed.ncbi.nlm.nih. } \\
\text { gov/21968612/ }\end{array}$ & $\begin{array}{l}\text { - Post care setting. } \\
\text { - This paper introduces an inter-professional clinical practice } \\
\text { guideline for vocational evaluation following traumatic brain } \\
\text { injury. This guideline aims to explicate the processes and factors } \\
\text { relevant to vocational evaluation to assist evaluators (i.e. health } \\
\text { care teams, individuals and employers) in collaboratively } \\
\text { determining if clients are able to work and to make } \\
\text { recommendations for work entry, re-entry or vocational planning. } \\
\text { - The resulting guideline includes } 17 \text { key recommendations within } \\
\text { the seven domains: (1) evaluation purpose and rationale; (2) initial } \\
\text { intake process; (3) assessment of the personal domain; (4) } \\
\text { assessment of the environment; (5) assessment of occupational/job } \\
\text { requirements; (6) analysis and synthesis; (7) evaluation } \\
\text { recommendations. }\end{array}$ & None indicated & Levels 1,2 \\
\hline
\end{tabular}


15. Traumatic brain injury clinical practice guidelines and best practices from the VA state of the art

conference.Scholten J, Vasterling JJ, Grimes JB. Brain Inj.

2017;31(9):1246-1251.

doi:10.1080/02699052.2016.

1274780. https://pubmed.ncbi.nlm.nih gov/28981348/

16. Traumatic brain injury: integrated approaches to improve prevention,

clinical care, and research. Maas AIR, Menon DK, Adelson PD, et al. Lancet Neurol. 2017;16(12):987-1048.

doi:10.1016/S1474-4422(17)30371-X.

https://pubmed.ncbi.nlm.nih. gov/29122524/

17. Continuum of care: Military health care providers and the traumatic brain injured service members. Doncevic S, Boerman HL. NeuroRehabilitation. 2010;26(3):285-290. doi:10.3233/NRE-2010-0564. https://pubmed.ncbi.nlm.nih. gov/20448318/
- Acute, subacute post care institutional.

Veterans Administration

Level 1

-

utilized the GRADE methodology to assess quality of evidence an determine the strength (i.e. weak or strong) of the recommendation such as For patients with history of TBI presenting with functional impairments due to dizziness, disequilibrium and spatial

disorientation symptoms, a short-term trial of specific vestibular,

visual and proprioceptive therapeutic exercise to assess the

individual patient responsiveness to treatment.

- A prolonged course of therapy in the absence of patient

improvement is strongly discouraged; Treatment of sleep

disturbance and headaches should be individualized and tailored to the clinical features and patient preferences; Patients with history of TBI presenting with symptoms related to memory, attention or executive function problems that do not resolve within 30-90 days be referred as appropriate to cognitive rehabilitation therapists with expertise in TBI rehabilitation.

- Consider a short-term trial of specific cognitive rehabilitation to assess the individual patient responsiveness to strategy training, including instruction and practice on use of memory aides to include assistive technology.

- This study assumes a broad overview for describing what is current and what is needed for management of TBI.

- Divides recommendations into prevention, prehospitalization, hospitalization and post-hospitalization.

- Treatment is divided into several domains: physical(eg speech, movement) behavioral(initiation, persistence etc), cognitive (memory, executive function etc), emotional (anger, anxiety etc), personal(family, social interaction) and environmental (access, technologies transportation etc).

- Categories of rehabilitation interventions for traumatic brain injury are Restitution (strengthening), Compensatory(functional substitution and assistive technology) and Adaptive (cognitive restructuring).

- The diversity and complexity of the consequences of TBI are best addressed with a comprehensive, holistic approach to rehabilitation delivered by a specialized multidisciplinary team, in close liaison with the patient and family or caregivers.

- Acute, Post care institutional care.

- Clinical Practice Guidelines have been created and distributed for treatment of TBI sustained by service members in both the deployed setting and in the continental United States (CONUS).

- The military has established specific levels of care each with specific purpose in the treatment continuum that extends from the battlefield to the most advanced military treatment facility (MTF)
Department of Defense and Veterans

Administration
Levels 1,2,

Expert Opinion
Brain Injury

 
Table 2

All entries were retrieved from database searches. None of the references identified specific rehabilitation prescriptions, but did mention recommendations for referral for general rehabilitation or physical/occupational therapies

\begin{tabular}{|c|c|c|}
\hline $\begin{array}{l}\text { TITLE + Citations + } \\
\text { Reference in text + URL }\end{array}$ & Summary & Reasons for exclusion \\
\hline $\begin{array}{l}\text { Clinical practice guidelines for } \\
\text { rehabilitation in traumatic brain injury: } \\
\text { a critical appraisal. Lee SY, Amatya B, } \\
\text { Judson R, et al. Brain Inj. } \\
\text { 2019;33(10):1263-1271. } \\
\text { https://pubmed.ncbi.nlm.nih. } \\
\text { gov/31314607/ } \\
\text { doi:10.1080/02699052.2019. } \\
\text { 1641747 }\end{array}$ & $\begin{array}{l}\text { - This review provides recommendations and quality of existing clinical } \\
\text { practice guidelines (CPGs) for the rehabilitaiton management of traumatic } \\
\text { brain injury (TBI) } \\
\text { - These CPGs are general and recommend comprehensive, flexible } \\
\text { coordinated multidisciplinary care and appropriate follow-up, education, and } \\
\text { support for patients with TBI (and care givers). } \\
\text { - Key rehabilitation recommendations: } 1 \text {.education, 2. physical rehabilitation, } \\
\text { 3.integrated computer-based management, 4. repetitive task-specific practice } \\
\text { in daily living activities, 5. safe equipment usage, } 6 \text {. cognitive/behavioral } \\
\text { feedback, 7. compensatory memory/visual strategies, } 8 \text {. Swallowing and } \\
\text { communication, and 9. psychological input for TBI survivors. }\end{array}$ & $\begin{array}{l}\text { This a literature review, } \\
\text { not a CPG. }\end{array}$ \\
\hline $\begin{array}{l}\text { Evidence-Based Cognitive } \\
\text { Rehabilitation: Systematic Review of } \\
\text { the Literature From } 2009 \text { Through } \\
\text { 2014. Cicerone KD, Goldin Y, Ganci } \\
\text { K, et al.Arch Phys Med Rehabil. } \\
\text { 2019;100(8):1515-1533. } \\
\text { doi:10.1016/j.apmr.2019.02.011. } \\
\text { https://pubmed.ncbi.nlm.nih. } \\
\text { gov/30926291/ }\end{array}$ & $\begin{array}{l}\text { - This systematic review of the clinical literature, classifies studies based on } \\
\text { the strength of research design, and derives consensual, evidence-based } \\
\text { clinical recommendations for cognitive rehabilitation of people with } \\
\text { traumatic brain injury (TBI) or stroke. } \\
\text { - Key recommendations: (1) identify attention deficits after TBI or stroke; (2) } \\
\text { visual scanning for neglect after right-hemisphere stroke; (3) compensatory } \\
\text { strategies for mild memory deficits; (4)speech language treatment for } \\
\text { left-hemisphere stroke; (5) address social communication deficits after TBI; } \\
\text { (6) metacognitive strategy training for deficits in executive functioning; and } \\
\text { (7) comprehensive-holistic neuropsychological rehabilitation to reduce } \\
\text { cognitive and functional disability after TBI or stroke. }\end{array}$ & $\begin{array}{l}\text { This a literature review, } \\
\text { not CPG. }\end{array}$ \\
\hline $\begin{array}{l}\text { Perioperative Management of Severe } \\
\text { Traumatic Brain Injury: What Is } \\
\text { New?Farrell D, Bendo AA. Curr } \\
\text { Anesthesiol Rep. 2018;8(3):279-289. } \\
\text { doi:10.1007/s40140-018-0286-1. } \\
\text { https://pubmed.ncbi.nlm.nih. } \\
\text { gov/30147453/ }\end{array}$ & $\begin{array}{l}\text { - This review discusses the current updates in the guidelines for the } \\
\text { perioperative management of TBI patients and describes potential new } \\
\text { therapies to improve functional outcomes. } \\
\text { - The major goal of perioperative management of TBI patients is to prevent } \\
\text { secondary damage. Use of established guidelines and recommendations } \\
\text { must be instituted promptly throughout the perioperative course to reduce } \\
\text { morbidity and mortality. }\end{array}$ & $\begin{array}{l}\text { This a literature review, } \\
\text { not a CPG. Description } \\
\text { of perioperative } \\
\text { management rather than } \\
\text { post care/ rehabilitation. }\end{array}$ \\
\hline $\begin{array}{l}\text { Preliminary guidelines for safe and } \\
\text { effective use of repetitive transcranial } \\
\text { magnetic stimulation in moderate to } \\
\text { severe traumatic brain injury. Nielson } \\
\text { DM, McKnight CA, Patel RN, Kalnin } \\
\text { AJ, Mysiw WJ. Arch Phys Med } \\
\text { Rehabil. 2015;96(4 } \\
\text { Suppl):S138-S144. } \\
\text { doi:10.1016/j.apmr.2014. } \\
09.010\end{array}$ & $\begin{array}{l}\text { - This article identifies guidelines for safe use of repetitive transcranial } \\
\text { magnetic stimulation(rTMS) in subjects with TBI based on a review of the } \\
\text { literature and illustrates their application with a case study. } \\
\text { - After } 6 \text { weeks of stimulation, the patient's depression was slightly improved, } \\
\text { and these improvements continued through follow-up. At the end of } \\
\text { follow-up, the patient's HAMD score was } 49 \% \text { of the average baseline score. }\end{array}$ & $\begin{array}{l}\text { This a literature review of } \\
\text { CPG. }\end{array}$ \\
\hline
\end{tabular}


MANAGING PATIENTS WITH

SEVERE traumatic brain injury.

Lump, Devon; Nursing, Mar2014

44(3): 30-38. 9p.

https://journals.lww.com/

nursing/Fulltext/2014/03000/

Managing_patients_with_severe

_traumatic_brain.9.aspx

Community based rehabilitation: special

issues. Neurorehabilitation. Martelli

MF, Zasler ND, Tiernan P.

2012;31(1):3-18.

doi:10.3233/NRE-2012-0770.

https://pubmed.ncbi.nlm.nih.

gov/22523014/

Rehabilitation of traumatic brain injury.

Levine JM, Flanagan SR. Psychiatr

Clin North Am. 2010;33(4):877-891.

doi:10.1016/j.psc.2010.09.001.

https://pubmed.ncbi.nlm.nih

gov/21093683/

Cognitive Rehabilitation After Traumatic Brain Injury: A Reference for

Occupational Therapists.Stephens JA,

Williamson K-NC, Berryhill ME.

OTJR: Occupation, Participation \&

Health. 2015;35(1):5-22.

doi:10.1177/1539449214561765
- This article discusses primary and secondary brain injuries,

recommendations for what should be included in nursing assessment and

initial treatment, medical and surgical management, postoperative care, and

long-term management for patients with severe TBI.

- This paper addresses some of the significant issues relevant to optimizing

long term adaptation for persons receiving community based rehabilitation.

- The article also addresses the current need for definitions, models, program

classifications and comparisons, as well as programmatic methodologies by attempting to integrate some of the best scientifically supported

methodologies within an eclectic holistic rehabilitation model that is easily understood and teachable to persons with TBI, families and rehabilitation professionals.

- Holistic neurorehabilitation programs are both evidence based and a practice standard based on literature review.

- Recommendations based onvliterature review and current practice.

- Rehabilitation following traumatic brain injury (TBI) is best provided by an interdisciplinary team of health care providers

- Successful rehabilitation requires prompt recognition and treatment of

TBI-related medical, cognitive, and behavioral problems to promote

recovery and enhance community reintegration, using a combination of rehabilitation modalities and medications.

- Literature review of interdisciplinary evidence-based practice targeting cognitive rehabilitation for civilian adults with TBI.

- Recommendations for early interventions: Intubation, Diagnosis, and

Surgical and Pharmaceutical Treatment, Cognitive assessment,

Contributions From Cognitive Neuroscience.

- Recommendations- Early intervention after TBI significantly improves

outcomes when compared with interventions that occur temporally later,One promising approach uses a combination of video and verbal feedback to improve self-awareness in patients without increasing emotional distress.Strategies that promote deeper memory encoding and slower information presentation facilitate learning in healthy individuals. One deep encoding technique, self-generation, asks individuals to create their own examples to understand new material. Individuals with TBI are able to use this strategy and subsequently enhance their learning ability.The cognitive orientation to occupational performance model (CO-OP) encourages individuals to use metacognitive strategies to identify and strengthen weak areas of cognition.
Mainly for educational purposes and not vetted

Not a vetted CPG

Not a vetted CPG.

Not a vetted CPG

(Continued) 
Table 2

(Continued)

TITLE + Citations +

Summary

Reasons for exclusion

Reference in text + URL

Comprehensive Systematic Review

Update Summary: Disorders of

Consciousness: Report of the

Guideline Development,

Dissemination, and Implementation

Subcommittee of the American

Academy of Neurology; the American

Congress of Rehabilitation Medicine;

and the National Institute on

Disability, Independent Living, and

Rehabilitation Research. Giacino JT,

Katz DI, Schiff ND, et al. Arch Phys

Med Rehabil. 2018;99(9):1710-1719.

doi:10.1016/j.apmr.2018.07.002.

https://doi.org/10.1016/

j.apmr.2018.07.002

Traumatic brain injury in adults. Kolias AG, Guilfoyle MR, Helmy A

Allanson J, Hutchinson PJ. Pract

Neurol. 2013;13(4):228-235.

doi:10.1136/practneurol-2012-000268.

https://pubmed.ncbi.nlm.nih.

gov/23487823/

Neuropsychological rehabilitation for

traumatic brain injury patients.

Chantsoulis M, Mirski A, Rasmus A,

Kropotov JD, Pachalska M. Ann Agric

Environ Med. 2015;22(2):368-379.

doi:10.5604/12321966.1152097.

https://pubmed.ncbi.nlm.nih.

gov/26094541/
- Clinicians should identify and treat confounding conditions, optimize

arousal, and perform serial standardized assessments to improve diagnostic

accuracy in adults and children with prolonged DoC (Level B). Clinicians

should counsel families that for adults, MCS (vs vegetative state

[VS]/unresponsive wakefulness syndrome [UWS]) and traumatic (vs

nontraumatic) etiology are associated with more favorable outcomes (Level

B). Pain always should be assessed and treated (Level B) and evidence

supporting treatment approaches discussed (Level B).

- Clinicians should prescribe amantadine (100-200 mg bid) for adults with

traumatic VS/UWS or MCS (4-16 weeks post injury) to hasten functional

recovery and reduce disability early in recovery (Level B). Family

counseling concerning children should acknowledge that natural history of

recovery, prognosis, and treatment are not established (Level B). Recent

evidence indicates that the term chronic VS/UWS should replace permanent

VS, with duration specified (Level B).

- This review presents the principles upon which modern TBI management should be based.

- The early management phase aims to achieve hemodynamic stability, limit secondary insults (e.g. hypotension, hypoxia), obtain accurate neurological assessment and appropriately select patients for further investigation.

Increase in recognition to manage the moderate to severe TBI patients in

Neuroscience centers regardless of their neurosurgical interventions.

- This review addresses what a comprehensive program of rehabilitation

should cover: 1. cognitive rehabilitation, 2 . individual and group

rehabilitation, 3. use of a therapeutic environment, 4. vocational

rehabilitation and family psychotherapy.

- These training programs are conducted within the scope of the "Academy of Life,' which provides support for the patients in their efforts and shows them the means by which they can overcome existing difficulties.
This is a CPG. It

discusses disorders of

consciousness and

includes TBI, but also

stroke and other

diagnostic groups.

They use American

Academy of Neurology manual. It is strong on

assuring quality

evidence. It lacks a

process to include

stakeholders or an

independent review of

recommendations. Has

a preponderance of

medication

recommendations

This a literature review, not CPG.

This a literature review not CPG. 
Information gathered from publications addressing TBI and rehabilitation which did not undergo a standard CPG vetting process, is also provided in a separate table for readers' comparison.

These 17 were further evaluated using the AGREE II template (Table 1). There were 4 that met all 6 criteria and 10 that met 5 . The missing domain was "editorial independence". One CPG met 3 criteria, one met 2 and one met one criterion. The CPG that only met a single criterion was reported as "Continuum of Care" and the other, that met only 2 criteria was titled "Best Practices".

During the review process, additional articles were identified that used CPGs in the title but were not, in fact CPGs. They were literature and systematic reviews of CPGs, practice guideline reviews and/or specialty societies appointed to develop guidelines without an established vetting process. These are presented in Table 2 (Chantsoulis et al., 2015; Cicerone et al., 2019; Farrell \& Bendo, 2018; Giacino et al., 2018; Kolias et al., 2013; Kondziella et al., 2020; Lee et al., 2019; Levine \& Flanagan, 2010; Lump, 2014; Martelli et al., 2012; Nielson et al., 2015; Stephens et al., 2015). One CPG was developed using a Delphi process following an American Academy of Neurology process (Giacino et al., 2018). While this is a rigorous approach to the quality of the publications reviewed, it omits several key features of the vetting process and was assigned to Table 2 .

\section{Discussion}

One of the most challenging tasks in the practice of medicine is to be sure of the effectiveness, safety and reliability of practice recommendations. These characteristics are essential if we wish to bring new, research findings into practice. Possible hurdles to accomplishing this goal, especially in clinical rehabilitation research, include the small sample sizes in most studies, the personalized nature of the deficits and disabilities, lack standardized interventions and common data elements for functional outcomes and dependencies on patient reported outcomes (Dijkers et al., 2020). These are challenges, but can be overcome and accommodated. Several researchers in the field of clinical rehabilitation research have been working on approaches to link best evidence within the context of the kind of research that is typically done in physical medicine and rehabilitation and preserve quality (Negrini, 2016, 2018).
Specifically, this review demonstrates several key themes evident from reviewing CPGs for people with TBI There is a paucity of intervention trials addressing rehabilitation outcomes for this population. We have chosen to include rehabilitation as a necessary component of the review, one that includes function as an outcome. This would, in our opinion, be especially valuable for the multi-disciplinary professionals from different backgrounds responsible for the care of people with TBI (E.g. neuropsychologists, physiatrists, occupational and physical therapists et al.).

In prior work (see Gerber, 2019, for more detail), it has been shown that there are relatively few intervention trials addressing functional outcomes for people with TBI and therefore, the number of publications available for systematic reviews is low. This creates a problem if one is to reach a high level of evidence. In this review, a total of 157 were found, 141 of these were eliminated from the final cut because they were not vetted or no vetting process was cited. Many of the CPGs addressed concussive injury rather than moderate to severe TBI, hence were eliminated for the purposes of this review. While not all of the final 17 CPGs that met inclusion criteria met the guidelines for AGREE II in all 6 domains, all met some and 4 met all.

An additional issue that needs to be addressed when applying CPGs is quality of the data supporting the recommendations. This was discussed in a recent publication (Dijkers et al., 2020). It reviewed the published CPG literature and determined that there has been an increase in the number of CPGs published over the past 20 years, reaching more than 7000 listed in PubMed as of May, 2020. In that review, the following search terms were used;, "(physical medicine)OR (rehabilitation) AND (clinical practice guideline) )". When approaching the question of quality, they applied the AGREE II template to CPGs. They reported that all 6 domains of the AGREEII were good predictors of quality, and that Domain 3 (rigor of development) was the strongest predictor, suggesting emphasis on rigor of development will improve quality among CPGS (Dijkers et al., 2020). Not all review processes apply the AGREE II template. Using it would be an important step forward.

Another important finding from this review is that the published guidelines frequently address issues of symptom control. Clearly, these are clinically important issues facing patients but, in the view of these authors, should be linked to functionally based outcome measures. For example, 6 CPGs addressed 
treatment of symptoms only (spasticity/deformity/ contractures, depression/anxiety, amnesia, memory loss, mental health, dizziness) with no mention as to whether there was a functional impact of symptom control. Nine used functional measures as primary or secondary outcomes for their studies and 2 of these provided an integrated approach to function across several domains of measure (impairment, functional limitation and participation) as well as in different stages of recovery. There were 2 studies that provided guidelines for the selection of outcome measures, both of which used a conceptual framework addressing the needs for people with TBI across the continuum of care and included multidomain measures. The use of outcome measures that address the functional needs of people with TBI is critical to assessing rehabilitation outcomes. The use of functional measures as primary or secondary outcomes is an important design feature of all clinical rehabilitation research. The acceptance of a multidomain model and effort to extend beyond the acute care setting into the community and assessment of independent living status is another desirable outcome for clinical rehabilitation research.

We made some choices as we planned this review. These included selecting publications that addressed moderate or severe TBI and not all brain injuries. This was arbitrary but is of significant concern because of its complexity, its need for coordinated rehabilitation interventions. Because of the multi-domain problems for people with moderate/severe TBI, we required that when rehabilitation intervention(s) were recommended, they needed to address a specific need and include specific interventions not only a comment "refer to rehabilitation, physical/occupational therapy". General referrals are frequently supported by expert opinion without literature resulting from intervention trials.

The items selected for inclusion in the tables, we hope, will provide readers with a ready reference to the CPGs that met criteria. As part of the vetting process, it is recommended that sponsors for CPG development be identified to be entirely transparent about whether there was funding for the effort. Occasionally, bias can be introduced into final recommendations for practice and readers should be aware of sponsors for the guideline development. Additionally, CPGs expand the knowledge base for treatment options when they consider important patient subgroups and patient preferences and provide a clear explanation of alternative care options and health outcomes. When studies CPG development was rigorous, but did not include these options, they were assigned to Table 2, which are informative and many have utility in advancing practice.

We acknowledge that concussive and mild TBI is prevalent, important and in need of continued research. However, because the level of severity, the types of interventions and determination for longer term followup in this population may require different research designs, treatments and data gathering approaches, we chose to address only moderate/severe TBI. Another decision was made to exclude publications published before 2010. This was decided because the field is changing quickly and the number of reviews, studies and practice changes are increasing rapidly and we wished the review to be current. We acknowledge that creating CPGs is time consuming and labor intensive and hence there is likely to be a significant amount of time that elapses between in preparation and publication. Nonetheless, currency is important in clinical care. We are surprised that some of the most comprehensive and well documented CPGs are more than 20 years old and have not been updated as of this review (Maas et al., 1997).

The development of reliable CPGs requires a careful, time consuming process. When done properly, we believe, they are an important resource for primary care practitioners, first responders and family who may have little experience with evaluating, transporting and managing problems associated with TBI. CPGs can provide needed, reliable and up to date information. In an under-sourced specialty such as physical medicine and rehabilitation, they are essential contributors to the field.

\section{Conclusion}

There are relatively few CPGs addressing rehabilitation for people with moderate or severe TBI. Remedies for this situation might include stimulation of more rehabilitation intervention trials, use of functional outcome measures as primary and/or secondary outcomes and possible inclusion of patients in selecting outcomes that are relevant and useful to this stakeholder group. One approach that may contribute to increasing the quality of CPGs, would be convening a group of investigators and relevant stakeholders to try to reach consensus on which measurements of function should be used in these studies. Commitment to strong metrics is likely to raise the level of evidence for intervention trials. Since many published 
CPGs have not been vetted to comply with published standards of reliability and trustworthiness for implementation for practice, journal editors should require all published CPGs to follow an accepted vetting process so that users are assured of their quality and trustworthiness. The addition of a template such as AGREE II, would also improve their quality.

\section{Conflict of interest}

The authors have nothing to declare.

\section{Funding}

This work was funded through a subcontract to Inova Health System from the American Institutes for Research, supported by NIDILRR Federal Grants \#90DP0082, \#90DPBU0001, and \#90DPBU0004.

\section{References}

Bayley, M. T., Tate, R., Douglas, J. M., Turkstra, L. S., Ponsford, J., Stergiou-Kita, M., Kua, A., Bragge, P., \& INCOG Expert Panel (2014). INCOG guidelines for cognitive rehabilitation following traumatic brain injury: methods and overview. The Journal of Head Trauma Rehabilitation, 29(4), 290-306. https://doi.org/10.1097/HTR.0000000000000070

Brain Trauma Foundation (2016). Guidelines for the Management of Severe Traumatic Brain Injury $4^{\text {th }}$ edition. Retrieved from http://braintrauma.org/uploads/03/12/Guidelines_for_Manag ement_of_Severe_TBI_4th_Edition.pdf

Brouwers, M. C., Kho, M. E., Browman, G. P., Burgers, J. S., Cluzeau, F., Feder, G., Fervers, B., Graham, I. D., Grimshaw, J., Hanna, S. E., Littlejohns, P., Makarski, J., Zitzelsberger, L., \& AGREE Next Steps Consortium (2010). AGREE II: advancing guideline development, reporting and evaluation in health care. Journal of Clinical Epidemiology, 63(12), 1308-1311. https:// doi.org/10.1016/j.jclinepi.2010.07.001

Brouwers, M. C., Kerkvliet, K., Spithoff, K., \& AGREE Next Steps Consortium (2016). The AGREE Reporting Checklist: a tool to improve reporting of clinical practice guidelines. BMJ (Clinical research ed.), 352, i1152. https://doi.org/ 10.1136/bmj.i1152

Chantsoulis, M., Mirski, A., Rasmus, A., Kropotov, J. D., \& Pachalska, M. (2015). Neuropsychological rehabilitation for traumatic brain injury patients. Annals of Agricultural and Environmental Medicine : AAEM, 22(2), 368-379. https://doi.org/10.5604/12321966.1152097

Cicerone, K. D., Goldin, Y., Ganci, K., Rosenbaum, A., Wethe, J. V., Langenbahn, D. M., Malec, J. F., Bergquist, T. F., Kingsley, K., Nagele, D., Trexler, L., Fraas, M., Bogdanova, Y., \& Harley, J. P. (2019). Evidence-Based Cognitive Rehabilitation: Systematic Review of the Literature From 2009 Through 2014.
Archives of Physical Medicine and Rehabilitation, 100(8), 1515-1533. https://doi.org/10.1016/j.apmr.2019.02.011

Corrigan, J. D., \& Hammond, F. M. (2013). Traumatic brain injury as a chronic health condition. Archives of Physical Medicine and Rehabilitation, 94(6), 1199-1201. https://doi.org/10.1016/j.apmr.2013.01.023

Dijkers, M. P., Ward, I., Annaswamy, T., Dedrick, D., Hoffecker, L., \& Millis, S. R. (2020). What determines the quality of rehabilitation Clinical Practice Guidelines? An overview study. American Journal of Physical Medicine \& Rehabilitation, 10.1097/PHM.0000000000001645. Advance online publication. https://doi.org/10.1097/PHM.0000000000001645

Doncevic, S., \& Boerman, H. L. (2010). Continuum of care: Military health care providers and the traumatic brain injured service members. NeuroRehabilitation, 26(3), 285-290. https:// doi.org/10.3233/NRE-2010-0564

Farrell, D., \& Bendo, A. A. (2018). Perioperative Management of Severe Traumatic Brain Injury: What Is New? Current Anesthesiology Reports, 8(3), 279-289. https://doi. org/10.1007/s40140-018-0286-1

Gerber, L. H., Bush, H., Cai, C., Garfinkel, S., Chan, L., Cotner, B., \& Wagner, A. (2019). Scoping review of clinical rehabilitation research pertaining to traumatic brain injury: 1990-2016. NeuroRehabilitation, 44(2), 207-215. https://doi. org/10.3233/NRE-182599

Giacino, J. T., Katz, D. I., Schiff, N. D., Whyte, J., Ashman, E. J., Ashwal, S., Barbano, R., Hammond, F. M., Laureys, S., Ling, G., Nakase-Richardson, R., Seel, R. T., Yablon, S., Getchius, T., Gronseth, G. S., \& Armstrong, M. J. (2018). Comprehensive systematic review update summary: Disorders of consciousness: Report of the Guideline Development, Dissemination, and Implementation Subcommittee of the American Academy of Neurology; the American Congress of Rehabilitation Medicine; and the National Institute on Disability, Independent Living, and Rehabilitation Research. Neurology, 91(10), 461-470. https://doi.org/10.1212/WNL.0000000000005928

Guyatt, G., Gutterman, D., Baumann, M. H., Addrizzo-Harris, D., Hylek, E. M., Phillips, B., Raskob, G., Lewis, S. Z., \& Schünemann, H. (2006). Grading strength of recommendations and quality of evidence in clinical guidelines: report from an american college of chest physicians task force. Chest, 129(1), 174-181. https://doi.org/10.1378/chest. 129.1.174

Guyatt, G. H., Oxman, A. D., Schünemann, H. J., Tugwell, P., \& Knottnerus, A. (2011). GRADE guidelines: a new series of articles in the Journal of Clinical Epidemiology. Journal of Clinical Epidemiology, 64(4), 380-382. https:// doi.org/10.1016/j.jclinepi.2010.09.011

Hammond, F. M., Corrigan, J. D., Ketchum, J. M., Malec, J. F., Dams-O'NConnor, K., Hart, T., Novack, T. A., Bogner, J., Dahdah, M. N., \& Whiteneck, G. G. (2019). Prevalence of Medical and Psychiatric Comorbidities Following Traumatic Brain Injury. The Journal of Head Trauma Rehabilitation, 34(4), E1-E10. https://doi.org/10.1097/HTR.0000000000000465

Hammond, F. M., Perkins, S. M., Corrigan, J. D., NakaseRichardson, R., Brown, A. W., O’Neil-Pirozzi, T. M., Zasler, N. D., \& Greenwald, B. D. (2021). Functional Change from Five to Fifteen Years after Traumatic Brain Injury. Journal of Neurotrauma, 38(7), 858-869. https://doi.org/10. 1089/neu.2020.7287

Honan, C. A., McDonald, S., Tate, R., Ownsworth, T., Togher, L., Fleming, J., Anderson, V., Morgan, A., Catroppa, C., Douglas, 
J., Francis, H., Wearne, T., Sigmundsdottir, L., \& Ponsford, J. (2019). Outcome instruments in moderate-to-severe adult traumatic brain injury: recommendations for use in psychosocial research. Neuropsychological Rehabilitation, 29(6), 896-916. https://doi.org/10.1080/09602011.2017.1339616

Institute of Medicine (US) Committee on Standards for Developing Trustworthy Clinical Practice Guidelines; Graham, R., Mancher, M., Wolman, D.M., Greenfield, S., \& Steinberg, E. (2011). Clinical Practice Guidelines We Can Trust. Washington (DC): National Academies Press (US).

Kolias, A. G., Guilfoyle, M. R., Helmy, A., Allanson, J., \& Hutchinson, P. J. (2013). Traumatic brain injury in adults. Practical Neurology, 13(4), 228-235. https://doi.org/10. 1136/practneurol-2012-000268

Kondziella, D., Bender, A., Diserens, K., van Erp, W., Estraneo, A., Formisano, R., Laureys, S., Naccache, L., Ozturk, S., Rohaut, B., Sitt, J. D., Stender, J., Tiainen, M., Rossetti, A. O., Gosseries, O., Chatelle, C., \& EAN Panel on Coma, Disorders of Consciousness (2020). European Academy of Neurology guideline on the diagnosis of coma and other disorders of consciousness. European Journal of Neurology, 27(5), 741-756. https://doi.org/10.1111/ene.14151

Kredo, T., Bernhardsson, S., Machingaidze, S., Young, T., Louw, Q., Ochodo, E., \& Grimmer, K. (2016). Guide to clinical practice guidelines: the current state of play. International journal for quality in health care: journal of the International Society for Quality in Health Care, 28(1), 122-128. https:// doi.org/10.1093/intqhe/mzv115

Laine, C., Taichman, D. B., \& Mulrow, C. (2011). Trustworthy clinical guidelines. Annals of Internal Medicine, 154(11), 774-775. https://doi.org/10.7326/0003-4819-154-11-201106070-00011

Lee, S. Y., Amatya, B., Judson, R., Truesdale, M., Reinhardt, J. D., Uddin, T., Xiong, X. H., \& Khan, F. (2019). Clinical practice guidelines for rehabilitation in traumatic brain injury: a critical appraisal. Brain Injury, 33(10), 1263-1271. https://doi.org/10.1080/02699052.2019.1641747

Levin H. (2016). France establishes guidelines for treating neurobehavioral disorders following traumatic brain injury. Annals of Physical and Rehabilitation Medicine, 59(1), 74-77. https://doi.org/10.1016/j.rehab.2015.06.005

Levine, J. M., \& Flanagan, S. R. (2010). Rehabilitation of traumatic brain injury. The Psychiatric clinics of North America, 33(4), 877-891. https://doi.org/10.1016/j.psc.2010.09.001

Lump D. (2014). Managing patients with severe traumatic brain injury. Nursing, 44(3), 30-38. https://doi.org/10.1097/ 01.NURSE.0000443311.50737.a8

Maas, A. I., Dearden, M., Teasdale, G. M., Braakman, R., Cohadon, F., Iannotti, F., Karimi, A., Lapierre, F., Murray, G., Ohman, J., Persson, L., Servadei, F., Stocchetti, N., \& Unterberg, A. (1997). EBIC-guidelines for management of severe head injury in adults. European Brain Injury Consortium. Acta neurochirurgica, 139(4), 286-294. https://doi. org/10.1007/BF01808823

Maas, A., Menon, D. K., Adelson, P. D., Andelic, N., Bell, M. J., Belli, A., Bragge, P., Brazinova, A., Büki, A., Chesnut, R. M., Citerio, G., Coburn, M., Cooper, D. J., Crowder, A. T., Czeiter, E., Czosnyka, M., Diaz-Arrastia, R., Dreier, J. P., Duhaime, A. C., Ercole, A., ... InTBIR Participants and Investigators (2017). Traumatic brain injury: integrated approaches to improve prevention, clinical care, and research. The Lancet. Neurology, 16(12), 987-1048. https://doi.org/10.1016/S14744422(17)30371-X
Malec, J. F., Ketchum, J. M., Hammond, F. M., Corrigan, J. D., Dams-O'NConnor, K., Hart, T., Novack, T., Dahdah, M., Whiteneck, G. G., \& Bogner, J. (2019). Longitudinal Effects of Medical Comorbidities on Functional Outcome and Life Satisfaction After Traumatic Brain Injury: An Individual Growth Curve Analysis of NIDILRR Traumatic Brain Injury Model System Data. The Journal of Head Trauma Rehabilitation, 34(5), E24-E35. https://doi.org/10. 1097/HTR.0000000000000459

Martelli, M. F., Zasler, N. D., \& Tiernan, P. (2012). Community based rehabilitation: special issues. NeuroRehabilitation, 31(1), 3-18. https://doi.org/10.3233/NRE-2012-0770

McCulloch, K. L., de Joya, A. L., Hays, K., Donnelly, E., Johnson, T. K., Nirider, C. D., Roth, H., Saliga, S., \& Ward, I. (2016). Outcome Measures for Persons With Moderate to Severe Traumatic Brain Injury: Recommendations From the American Physical Therapy Association Academy of Neurologic Physical Therapy TBI EDGE Task Force. Journal of neurologic physical therapy : JNPT, 40(4), 269-280. https:// doi.org/10.1097/NPT.0000000000000145

Moher, D., Shamseer, L., Clarke, M., Ghersi, D., Liberati, A., Petticrew, M., Shekelle, P., Stewart, L. A., \& PRISMA-P Group (2015). Preferred reporting items for systematic review and meta-analysis protocols (PRISMA-P) 2015 statement. Systematic reviews, 4(1), 1. https://doi.org/10.1186/2046-4053-4-1

Negrini, S., Kiekens, C., Levack, W., Grubisic, F., Gimigliano, F., Ilieva, E., \& Thorsten, M. (2016). Cochrane physical and rehabilitation medicine: a new field to bridge between best evidence and the specific needs of our field of competence. European Journal of Physical and Rehabilitation Medicine, 52(3), 417-418.

Negrini, S., Arienti, C., Gimigliano, F., Grubišić, F., Howe, T., Ilieva, E., Levack, W., Malmivaara, A., Meyer, T., Patrick Engkasan, J., Rathore, F. A., \& Kiekens, C. (2018). Cochrane Rehabilitation: Organization and Functioning. American Journal of Physical Medicine \& Rehabilitation, 97(1), 68-71. https://doi.org/10.1097/PHM.0000000000000832

Nielson, D. M., McKnight, C. A., Patel, R. N., Kalnin, A. J., \& Mysiw, W. J. (2015). Preliminary guidelines for safe and effective use of repetitive transcranial magnetic stimulation in moderate to severe traumatic brain injury. Archives of Physical Medicine and Rehabilitation, 96(4 Suppl), S138-S144. https://doi.org/10.1016/j.apmr.2014.09.010

New Zealand Guidelines Group (2006). The Diagnosis, Acute Management and Rehabilitation of People with Traumatic Brain Injury. Retrieved from https://www.moh.govt. nz/NoteBook/nbbooks.nsf/0/B8738C3605889A6ACC257A6 D00809243/\$file/060831_TBI_Evidence_Tables_Final.pdf

Ontario Neurotrauma Foundation (2015). INESSS-ONF Clinical Practice Guidelines for the Rehabilitation of Adults with Moderate to Severe Traumatic Brain Injury. Retrieved from https:// onf.org/knowledge-mobilization/acquired-brain-injury/gui delines-for-concussion-and-moderate-to-severe-traumaticbrain-injury/

Oxford Centre for Evidence-based Medicine (2009). Levels of evidence. CEBM. Retrieved from https://www.cebm.net/ 2009/06/oxford-centre-evidence-based-medicine-levels-evi dence-march-2009/

Patel, A., Vieira, M. M., Abraham, J., Reid, N., Tran, T., Tomecsek, K., Vissoci, J. R., Eucker, S., Gerardo, C. J., \& Staton, C. A. (2016). Quality of the Development of Traumatic Brain Injury Clinical Practice Guidelines: A Systematic 
Review. PloS one, 11(9), e0161554. https://doi.org/10.1371/ journal.pone.0161554

Pattuwage, L., Olver, J., Martin, C., Lai, F., Piccenna, L., Gruen, R., \& Bragge, P. (2017). Management of Spasticity in Moderate and Severe Traumatic Brain Injury: Evaluation of Clinical Practice Guidelines. The Journal of Head Trauma Rehabilitation, 32(2), E1-E12. https://doi.org/10. 1097/HTR.0000000000000234

Ponsford, J., Bayley, M., Wiseman-Hakes, C., Togher, L., Velikonja, D., McIntyre, A., Janzen, S., Tate, R., \& INCOG Expert Panel (2014). INCOG recommendations for management of cognition following traumatic brain injury, part II: attention and information processing speed. The Journal of Head Trauma Rehabilitation, 29(4), 321-337. https://doi.org/ 10.1097/HTR.0000000000000072 https://www.guidelinecen tral.com/summaries/brain-injury-rehabilitation-in-adults-anational-clinical-guideline/\#section-396

Ponsford, J., Janzen, S., McIntyre, A., Bayley, M., Velikonja, D., Tate, R., \& INCOG Expert Panel (2014). INCOG recommendations for management of cognition following traumatic brain injury, part I: posttraumatic amnesia/delirium. The Journal of Head Trauma Rehabilitation, 29(4), 307-320. https:// doi.org/10.1097/HTR.0000000000000074

Scholten, J., Vasterling, J. J., \& Grimes, J. B. (2017). Traumatic brain injury clinical practice guidelines and best practices from the VA state of the art conference. Brain Injury, 31(9), 12461251. https://doi.org/10.1080/02699052.2016.1274780

Stephens, J. A., Williamson, K. N., \& Berryhill, M. E. (2015). Cognitive Rehabilitation After Traumatic Brain Injury: A Reference for Occupational Therapists. OTJR : Occupation, Participation and Health, 35(1), 5-22. https://doi.org/10. 1177/1539449214561765

Stergiou-Kita, M., Dawson, D., \& Rappolt, S. (2012). Interprofessional clinical practice guideline for vocational evaluation following traumatic brain injury: a systematic and evidence-based approach. Journal of Occupational Rehabilitation, 22(2), 166-181. https://doi.org/10.1007/s10926-0119332-2
Tate, R., Kennedy, M., Ponsford, J., Douglas, J., Velikonja, D., Bayley, M., \& Stergiou-Kita, M. (2014). INCOG recommendations for management of cognition following traumatic brain injury, part III: executive function and self-awareness. The Journal of Head Trauma Rehabilitation, 29(4), 338-352. https://doi.org/10.1097/HTR.0000000000000068

Togher, L., Wiseman-Hakes, C., Douglas, J., Stergiou-Kita, M., Ponsford, J., Teasell, R., Bayley, M., Turkstra, L. S., \& INCOG Expert Panel (2014). INCOG recommendations for management of cognition following traumatic brain injury, part IV: cognitive communication. The Journal of Head Trauma Rehabilitation, 29(4), 353-368. https://doi.org/10. 1097/HTR.0000000000000071

U.S. Preventive Services Task Force (2018). Grade definitions. Retrieved from https://www.uspreventiveservice staskforce.org/uspstf/grade-definitions

Uomoto J. M. (2012). Best practices in veteran traumatic brain injury care. The Journal of Head Trauma Rehabilitation, 27(4), 241-243. https://doi.org/10.1097/HTR.0b013e31825ee26a

Velikonja, D., Tate, R., Ponsford, J., McIntyre, A., Janzen, S., Bayley, M., \& INCOG Expert Panel (2014). INCOG recommendations for management of cognition following traumatic brain injury, part V: memory. The Journal of Head Trauma Rehabilitation, 29(4), 369-386. https://doi.org/10. 1097/HTR.0000000000000069

World Health Organization (2018). International classification of functioning, disability and health. Retrieved from http://www. who.int/classifications/icf/en/ 